\title{
Pengaruh Trust Dan E-Service Terhadap Repurchase Intention Bagi Pengguna Aplikasi Shopee
}

\author{
Reni Nilasari ${ }^{1}$ \\ Fakultas Ekonomi dan Bisnis \\ Universitas Airlangga, Indonesia \\ Email: nilasarireni2@gmail.com
}

\begin{abstract}
ABSTRAK
Aplikasi modern tentunya membutuhkan sistem yang tersusun rapi, sehingga memudahkan konsumen untuk menggunakannya. Kepercayaan adalah hal penting yang diperlukan situs online karena secara logis konsumen memiliki tingkat risiko yang lebih tinggi dalam transaksi online dibandingkan dengan transaksi offline dalam hal pengiriman, pembayaran, dan informasi pribadi. Tujuan dari penelitian ini adalah untuk mengetahui bagaimana trust dan e-service dapat mempengaruhi Repurchase intention pada pengguna aplikasi shopee. Analisis menggunakan regresi berganda dengan data dari penelitian ini 128 responden pengguna aplikasi shopee. Hasilnya trust dan e-sercive memiliki efek positif pada repurchase intention.
\end{abstract}

Kata Kunci : $\quad$ Trust, E-service; Repurchase Intention; Shopee.

The Effect of Trust and E-Service on Repurchase Intention For Shopee Application Users

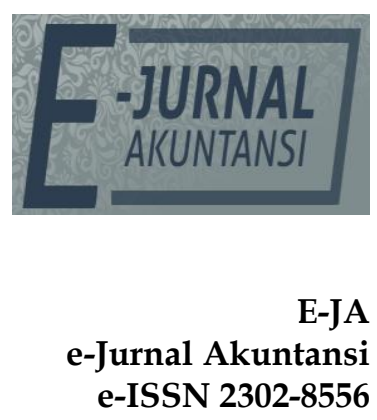

Vol. 29 No. 2

Denpasar, November

2019

ABSTRACT

Modern applications certainly require a neatly arranged system, making it easier for consumers to use it. Trust is an important thing that online sites need because logically consumers have a higher level of risk in online transactions compared to offline transactions in terms of shipping, payment, and personal information. The purpose of this study is to find out how trust and e-service can affect Repurchase intention in shopee application users. Analysis using multiple regression with data from this study 128 respondents shopee application users. The result is trust and eservice have a positive effect on repurchase intention.

Keywords: $\quad$ Trust, E-service; Repurchase Intention; Shopee. 


\section{PENDAHULUAN}

Kemajuan teknologi mempengaruhi pola berbelanja yang awalnya masih dengan cara tradisional saat ini sudah beralih menggunakan cara yang lebih modern. Semakin meningkatnya keperluan seseorang terhadap informasi memberikan peningkatan pada perkembangan teknologi dalam memberikan informasi tersebut (Saragih dan Ramdhany, 2016). Kebutuhan manusia akan pememuhan kebutuhan sehari-hari seperti pakaian, makanan, alat-alat elektronik, dan kebutuhan rumah tangga lainnya (Picaully, 2018). Kemudahan teknologi ini dalam memenuhi kebutuhan manusia menjadi lebih mudah dengan tersedianya aplikasi shopee ini memudahkan kita untuk berbelanja. Dengan menggunakan sebuah aplikasi semua orang dapat berbelanja dimanapun dan kapanpun, hanya dengan berdiam dirumah kita sudah bisa membeli barang-barang kebutuhan yang kita perlukan memalui transaksi online ini baik dalam maupun luar negeri. Shopee merupakan sebagian besar media online yang ada di Indonesia yang melayani konsumen dengan belanja secara online. Dengan adanya belanja online ini yang didalamnya menyediakan produk seperi makanan, minuman, pakaian, peralatan rumah tangga, aksesoris, elektronik, dan lainya diharapkan mampu menyalurkan kebutuhan para konsumenya. Shopee memberikan fasilitas lengkap mulai dari para penjual yang ingin berjualan dan juga menyediakan pembayaran secara elektronik namun tetap memberikan rasa aman sehingga konsumen mendapatkan rasa percaya terhadap aplikasi ini (Meidita, Suprapto, dan Rokhmawati, 2016).

Saat ini maraknya aplikasi berbelanja online namun aplikasi shopee adalah salah satu aplikasi yang baru hadir di Indonesia, sebelumnya sudah banyak aplikasi yang serupa namun shopee hadir lebih banyak fitur dan transaksi elektronik yang aman digunaakan kosnumennya. Shopee memberikan layanan elektronik merupakan sebuah sistem yang dapat terintegrasi dan aman sehingga konsumenya pun akan memiliki rasa trust (percaya) yang ini penting sekali bagi para konsumen agar terhindar dari risiko yang tinggi dalam bertransaksi secara online. Tingkat kepercayaan sendiri merupakan pemikiran konsumen bahwa para penjual berprilaku baik dan jujur atas barang yang yang dijualnya. Tingkat layanan elektronik merupakan alat kepercayaan yang memberikan layanan berkualitas tinggi sehingga perlu peningkatan dalam tingkat komunikasi dengan pelanggan (Rostami, Amir dan Soltani, 2016). Menurut (Razak, Ahmad dan Marimuthu, 2016) tingkat layanan merupakan peran penting dalam mempengaruhi pembelian pelanggan online. Kualitas layanan merupakan konsep multidimentional dan juga sebagai kualitas layanan tradisional. Hal ini dapat diartikan bahwa kulitas layanan bagian dari kepuasan pelanggan (Bao, 2015). Repurchase intention merupakan elemen yang paling didambakan dianatara pengecer online (Razak, Ahmad dan Marimuthu, 2016) (Bao, 2015) menurutnya repurchase intention adalah bentuk dari niat prilaku.

Repurchase intention menurut (Razak, Ahmad, dan Marimuthu, 2016) merupakan elemen-elemen yang memberikan kepuasan dan kesetiaan dari pelanggan. Bao (2015) mendefinisakn repurchase intention sebagai niat prilaku pelangganya ketika merasa aman dan puas ketika berbelanja. Selain itu Kaveh, (2012) menjelaskan bahwa repurchase intention merupakan kepuasan pelanggan bagian dari prilaku niat untuk membeli kembali. (Bani Ismoyo, 2018) repurchase 
intension dapat dipengaruhi oleh kualitas layanan yang diberikan oleh perusahaan sehingga mampu memberikan kepuasan atas layanan tersbut kepada pelangganya. Saragih dan Ramdhany, (2016) dan (Santoso dan Aprianingsih, 2017) menunjukan bahwa adanya kualitas layanan mempunyai pengaruh pada keinginan niat untuk membeli kembali secara online.

Penelitian yang mendukung tingkat Repurchase intention juga dilakukan oleh (Saleem dkk., 2017) bahwa niat membeli kembali dapat mempengaruhi pola pikir pelanggannya hal ini juga dapat mempengeruhi komitmen masa depan untuk membeli kembali. Kepercayaan dan kualitas layanan dapat mempengaruhi kepuasan pelanggannya dan niat membeli kembali (Gera, 2013). Baskol (2016) repurchase intention juga dipengaruhi oleh kualitas layanan yang meberikan tingkat kepuasan terhadap pelanggannya. Shahrokh, Oveisi, dan Timasi (2013) bahwa repurchase intention dipengaruhi oleh loyalitas pelanggan. (Setyorini dan Prima, 2015) menyatakan bahwa terdapat pengaruh kepercayaan pada Repurchase intention. Tingkat kepuasaan pelanggan dapat memepengaruhi niat membeli kembali (Posselt dan Gerstner, 2005).

Menurut (Kaveh, 2012) kepercayaan atau Trust berhubungan dengan disposisi antara menguntungkan atau tidak menguntungkan sehubung dengan yang pelanggan terima. Ketika pelanggan merasa diuntungkan maka dia akan percaya, namun sebaliknya jika objek yang diterima tidak menguntungkan maka dia tidak percaya untuk berbelanja. Nurlita (2017)ada beberapa faktor mampu memberikan kepercayaan bagi pembeli untuk belanja online yaitu, pembeli memiliki informasi teknologi, situs web yang terjamin, dan kualitas dari perusahaan. Dalam penelitian Nurlina menemukan bahwa kepercayaan merupakan pengaruh positif terhadap niat untuk membeli. Dalam penelitian yang dilakukan oleh (Saleem, Zahra, dan Yaseen, 2017) bahwa kepercayaan mempengaruhi niat membeli kembali. Kepercayaan pelanggan dapat memepengaruhi niat pembelian kembali (Setyorini dan Prima, 2015). Saragih dan Ramdhany (2016) menunjukan bahwa kepercayaan tidak berpengaruh positif terhadap keinginan untuk membeli kembali berbasis online. Azemi, Baholli dan Guberaj (2015) kepercayaan memiliki pengaruh positif terhadap loyalitas pelanggan. Kepercayaan sangat diperlukan untuk membangun kepercayaan diri sehingga ransaksi online dapat diselesaikan. Berdasarkan penelitian terdahulu hipotesis pada penelitian adalah:

$\mathrm{H}_{1}$ : Apakah trust memiliki pengaruh terhadap repurchase intention.

Menurut Razak, Ahmad dan Marimuthu, (2016) e-service merupakan alat yang dapat meningkatkan layanan pelanggan termasuk halaman web yang dipersonalisasi, daftar kategori layanan interaktivitas dan responsive. Bao (2015) E-Service adalah kualitas layanan yang diberikan untuk pelangganya. Menurut Kaveh (2012) bahwa e-service adalah hasil perbandingan antara apa yang dianggap konsumen sebagai layanan dan mereka mengetahui tentang kinerja yang ditawarkan oleh penyedia layanan.

Hal ini didukung oleh penelitian yang dilakukan oleh (Ismoyo, 2018) menyatakan kualitas layanan dapat memberikan pengaruh pada kepuasan konsumen yang menyebabkan pelanggan tersebut berniat membeli kembali produknya. Nurlita (2017) menyatakan pengaruh positif pada kualitas layanan terhadap niat untuk beli kembali produk. Santoso dan Aprianingsih (2017) 
menyatakan adanya pengaruh pada tingkat layanan secara online berpengaruh positif pada niat untuk membeli kembali. Artinya pelayanan yang diberikan perusahaan mampu memberikan kepuasan sehingga pelanggan ingin membeli kembali. Azemi (2015) menemukan hubungan positif kualitas layanan terhadap loyalitas pelanggan. Dimana kualitas layanan diibarakan budaya yang memang meiliki pengaruh pada kesetiaan pelanggannya. Saleem dkk., (2017) bahwa kualitas layanan dapat mempengaruhi niat membeli kembali pelangganya. Oleh sebeb itu pemahaman kualitas layanan menjadi sangat penting untuk perencanaan strategis dan taktis. Kualitas layanan elektronik dalam mengembangkan konteks pasar dapat memepengaruhi tingkat kepuasan pelanggan dan hasilnya mereka berniat untuk membeli kembali dimasa depan (Gera, 2013). Berdasarkan penelitian terdahulu hipotesis penelitian ini adalah:

$\mathrm{H}_{2}$ : Apakah e-service memiliki pengaruh terhadap repurchase intention.

Jenis penelitian ini menggunakan penelitian kuantitatif. Populasi penelitian yaitu pengguna aplikasi Shopee. Data yang digunakan berupa kuesioner sebanyak 128 responden. Berdasarkan teori dan hipotesis maka kerangka pemikiran dalam penelitian ini adalah:

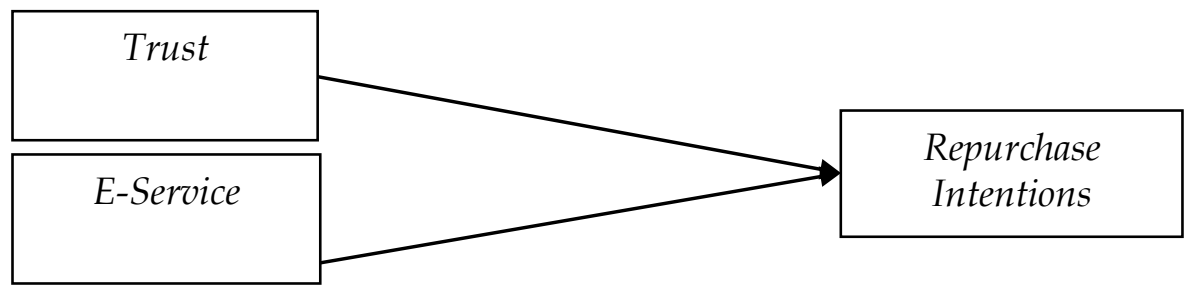

Gambar 1. Model Penelitian

Sumber: Data Penelitian, 2019

\section{METODE PENELITIAN}

Penelitian ini merupakan penelitian kuantitatif. Populasi penelitian yaitu seseorang yang pernah berbelanja dengan menggunakan aplikasi Shopee. Jenis data dalam penelitian ini adalah data primer berupa data kuesioner dan diperoleh data sebanyak 128 responden yang pernah menggunakan aplikasi shopee. Metode analisis data yang digunakan pada penelitian ini adalah analisis regresi berganda. Adapun langkah dalam menganalisis yaitu dengan melakukan uji statistik deskriptif, Uji statistic F (F-Test) digunakan untuk menguji pengaruh variable independen terhadap variable dependen secara simultan (bersamasama). Uji F digunakan untuk menguji kelayakan model regresi dalam penelitian. Uji hipotesis atau uji $\mathrm{T}$ pada dasarnya menunjukan seberapa jauh pengaruh satu variabel independen secara individual dalam menerangkan variabel dependen.

Repurchase intentions merupakan aktivitas untuk melakukan pembelian kembali produk sebanyak dua atau lebih baik produk yang sama maupun berbeda(Zeng, Hu, Chen, dan Yang, 2009). Bao (2015) mendefiniskan repurchase intention sebagai niat prilaku pelangganya ketika merasa aman dan puas ketika berbelanja. Trust atau kepercayaan merupakan dasar dari kegiatan bisnis yang menyangkut transaksi bisnis antar pihak. Menurut (Kaveh, 2012) kepercayaan atau Trust berhubungan dengan disposisi antara menguntungkan atau tidak 
menguntungkan sehubung dengan yang pelanggan terima. Menurut Razak, Ahmad dan Marimuthu, (2016) e-service merupakan alat yang dapat meningkatkan layanan pelanggan termasuk halaman web yang dipersonalisasi, daftar kategori layanan interaktivitas dan responsive.

\section{HASIL DAN PEMBAHASAN}

Berdasarkan populasi dan sampel yang didapat sebanyak 128 responden pada penelitian ini. Uji regresi digunakan untuk menguji ada tidaknya pengaruh variabel bebas terhadap variabel terikat tentang pengaruh trust dan e-service terhadap repurchase intention dengan analisis regresi berganda.

Tabel 1. Hasil statistik deskritif

\begin{tabular}{lcccc}
\hline \multicolumn{5}{c}{ Descriptive Statistics } \\
\hline X1 & N & Minimum & Maximum & Mean \\
X2 & 128 & 5 & 14 & 9,28 \\
Y & 128 & 7 & 20 & 12,60 \\
Valid N (listwise) & 128 & 3 & 10 & 5,83 \\
\hline
\end{tabular}

Sumber: Data Penelitian, 2019

Tabel 1. menunjukan bahwa jumlah sampel (N) sebanyak 128 responden.. Dengan nilai rata-rata trust sebesar 9,29 ini menunjukan bahwa reponden setuju dengan pernyataan trust. Nilai rata-rata e-service sebesar 12,60 artinya responden setuju dengan pernyataan yang ada pada e-service dan rata-rata nilai repurchase intentions sebesar 5.83 maka responden bersedia dan memiliki repurchase intentions untuk belanja di shopee kembali.

Tabel 2. Hasil Analisis Regresi Linier Berganda

\begin{tabular}{llccccc}
\hline \multirow{2}{*}{ Model } & \multicolumn{2}{c}{$\begin{array}{c}\text { Unstandardized } \\
\text { Coefficients }\end{array}$} & $\begin{array}{c}\text { Standardized } \\
\text { Coefficients }\end{array}$ & $\mathrm{t}$ & Sig. \\
\cline { 3 - 5 } & \multicolumn{2}{c}{ B } & Std. Error & Beta & & \\
\hline & (Constant) & 1,057 & 0,586 & & 1,803 & 0,074 \\
& X1 & 0,315 & 0,067 & 0,395 & 4,665 & 0,000 \\
& X2 & 0,147 & 0,044 & 0,280 & 3,307 & 0,001 \\
& & & & & \\
F & 33,947 & & & & \\
Sig. & $0,000^{\text {a }}$ & & & & \\
\hline
\end{tabular}

Sumber: Data Penelitian, 2019

Berdasarkan hasil analisis regresi pada tabel 2. dapat dijelaskan bahwa koefisien konstanta (a) sebesar 1,057 yang menunjukan besarnya variable yang terikat (Y) apabila variable bebasnya (TR dan ES) sebesar konstan. Koefisien regresi trust (b1) sebesar 0,315 menunjukan bahwa variable bebas trust naik sebesar satu satuan, maka variable terikat $\mathrm{Y}$ (repurchase intentions) akan meningkat sebesar 0,315 satuan. Dan koefisien e-service (b2) sebesar 0,147 menunjukan bahwa variable bebas e-service naik sebesar satu satuan, maka variable terikat $Y$ (repurchase intentions) akan meningkat sebesar 0,147 satuan.

Hasil analisis uji $\mathrm{F}$ dapat dilihat pada tabel berikut ini:

$$
\mathrm{Y}=1,057+0.315+0,147
$$


Analisis uji $\mathrm{F}$ ini digunakan untuk menguji secara bersama variabel bebas yaitu X1 (trust) dan X2 (e-service) secara bersama mempengaruhi variabel terikat $\mathrm{Y}$ (repurchase intentions)

Tabel 3. Hasil Analisis Uji F

\begin{tabular}{lccccc}
\hline Model & Sum of Squares & df & Mean Square & F & Sig. \\
\hline Regression & 75,399 & 2 & 37,700 & 33,947 & $0,000^{a}$ \\
Residual & 138,819 & 125 & 1.111 & & \\
Total & 214,219 & 127 & & &
\end{tabular}

a. Predictors: (Constant), X1, X2

b. Dependent Variable: $Y$

Sumber: Data Penelitian, 2019

Berdasarkan tabel 3. diketahui bahwa nilai signifikan 0,00 kurang dari 0,05. Dengan demikian dapat disimpulkan bahwa model telah fit dan dapat digunakan untuk memprediksi pengaruh kepercayaan dan kualitas layanan terhadap niat untuk membeli kembali.

Tabel 4. Hasil Analisis Uji T

\begin{tabular}{llrrrrr}
\hline \multirow{2}{*}{ Model } & \multicolumn{3}{c}{$\begin{array}{c}\text { Standardized } \\
\text { Coefficients }\end{array}$} & & \multirow{2}{*}{ Sig. } \\
\cline { 3 - 5 } & \multicolumn{1}{c}{ Unstandardized Coefficients } & & \\
\hline 1 & (Constant) & 1,057 & 0,586 & & 1.803 & 0,074 \\
& X1 & 0,315 & 0,067 & 0,395 & 4.665 & 0,000 \\
X2 & 0,147 & 0,044 & 0,280 & 3.307 & 0,001
\end{tabular}

a. Dependent Variable: $Y$

Sumber: Data Penelitian, 2019

Berdasarkan pengujian hipotesis pertama pada tabel 4. menunjukan bahwa Trust mempunyai nilai beta sebesar 0,315 terhadap repurchase intention. Dengan nilai signifikansi sebesar 0,000 maka Ho ditolak dan Ha diterima. Oleh karena itu disimpulkan bahwa adanya trust berpengaruh positif dan memiliki nilai signifikan pada niat untuk membeli kembali. Trust merupakan hubungan saling percaya dalam dunia offline menjadi pembahasan yang banyak dibicarakan dalam disiplin ilmu, namun kepercayaan dalam dunia online masih memerlukan konsep. Dengan banyaknya kasus, aturan dan regulasi dapat memungkinkan konsumen untuk mengatasi kompleksitas yang mungkin terjadi yang menyebabkan adanya tindakan yang dapat mempengaruhi kepercayaan. Meski banyak orang yang memiliki pendapat berbeda tentang makna kepercayaan online ini, namun dampak kepercayaan atau trust pelanggan terhadap belanja online tidak diragukan lagi. Trust muncul sebagai aspek yang sangat potensial yang berpotensi mengarah ke lingkungan e-commerce (Razak, Omar, dan Mamat, 2014). Hal sama dengan penelitian yang dilakukan oleh (Saleem dkk., 2017) bahwa kepercayaan mempengaruhi niat membeli kembali. Kepercayaan pelanggan dapat memepengaruhi niat pembelian kembali (Setyorini dan Prima, 2015). 
Trus sangat diperlukan dalam mendapatkan dan mempertahankan konsumen untuk melakukan repurchase intentions melalui belanja online dengan menggunakan aplikasi shopee dimasa mendatang. Karena trust tidak hanya begitu saja dapat diakui oleh pihak lain atau mitra, oleh karena itu harus dibangun mulai dari awal dan dapat dibuktikan. Trust menjadi salah satu pertimbangan atas transaksi antar penkjual dan pembeli agar kepuasan konsumen dapat terwujud dan sesuai dengan apa yang diharapkan oleh pelanggan. Dalam teori (Morgan dan Hunt, 1994) trus akan terbentuk jika pelaku bisnis dapat mempercayai reliability dan integrity dari pelaku bisnis lainnya. Reliabilitas sendiri merupakan kepercayaan konsumen yang didasari seberapa jauhkah konsumen dapat menaruh harapan terhadap perusahaan dalam memberikan pelayanan seperti yang sudah dijanjika. Sedangkan integritas adalah sebuah pilihan pribadi yang secara konsisten terhadap suatu komitmen untuk menghormati moral, etika, spiritual dan niali dari sebuah prinsip atau aturan.

Hipotesis kedua pada tabel 4. menunjukan bahwa E-Service mempunyai nilai beta sebesar 0,147 terhadap repurchase intention. Dengan demikian nilai signifikansi sebesar 0,001 maka Ho ditolak dan Ha diterima. Oleh karenanya dapat disimpulkan bahwa E-Service berpengaruh positif dan memiliki nilai signifikan terhadap niat untuk membeli kembali. E-service merupakan gambaran dari penilaian konsumen atas penyediaan layanan apakah sudah sesuai dengan keinginan dan harapan dari pelanggan sehingga dapat mempengaruhi pembeli untuk melakukan repurchase intentions dimasa mendatang. Dengan adanya $e-$ service menjadi salah satu kompetensi bagi perusahaan online dalam memberikan layanan yang baik dan aman bagi pelangganya. Pentingnya e-service menjadi salah satu kebutuhan bagi perusahaan online (Chen, Li, dan Liu, 2019) dan (Javed dan $\mathrm{Wu}, 2019)$. Kim, Cho, dan Kim (2019) e-service memberikan informasi dan layanan yang cukup baik pada pelanggan. Hal ini untuk mengurangi ketidaknyamanan yang dirasakan oleh pelanggan dalam membeli produk. Menurut (Buchari, 2016) e-service merupakan gambaran dari tiga komponen yaitu, layanan, penerima layanan dan saluran pelayanan dari teknologi.

Berdasarkan penelitian yang sama dengan penelitian yang dilakukan oleh oleh (Ismoyo, 2018) menemukan bahwa service quality mempengaruhi kepuasan konsumen yang menyebabkan pelanggan tersebut berniat membeli kembali produknya. Nurlita (2017) menunjukan bahwa terdapat adanya pengaruh positif kualitas layanan terhadap niat membeli produk. Santoso dan Aprianingsih (2017) menunjukan bahwa kualitas dari layanan elektronik berpengaruh positif terhadap niat untuk membeli kembali.

\section{SIMPULAN}

Ketika pelanggan merasa diuntungkan maka dia akan percaya, namun sebaliknya jika objek yang diterima tidak menguntungkan maka dia tidak percaya untuk berbelanja. Trust sangat diperlukan untuk membangun kepercayaan diri sehingga ransaksi online dapat diselesaikan. e-service adalah kualitas layanan yang diberikan untuk pelangganya (Bao, 2015). Ketika perusahaan dapat memberikan pelayanan terbaik kepada pelanggannya maka 
sebenarnya perusahaan mendapatkan kepercayaan dari konsumennya sehingga mereka akan menjadi pelanggan setianya.

Implikasi berdasarkan hasil analisis data yang ditemukan bahwa trust dan e-service merupakan variabel yang dapat memberikan pengaruh positif pada repurchase intention. Oleh karena itu shopee harus tetap mempertahankan dan meningkatkan pelayanan yang baik sehingga konsumen memiliki tingkat trust yang tinggi untuk berbelanja kembali lebih dari sekali tentunya dengan mengupgrade sistemnya. Dari hasil penelitian ini penulis memberikan saran pertama, untuk pihak perusahaan Shopee untuk lebih memberikan kemudahan dalam proses berbelanja secara online dengan prosedur yang sederhana dan terintegrasi maka konsumen semakin tertarik. Kedua, utamakan agar menjaga trust konsumen. Keterbatasan dalam penelitian ini adalah dari jutaan konsumen kami hanya mendapatkan 128 responden sehingga masih terlalu sedikit untuk mewakili jumlah konsumen.

\section{REFERENSI}

Azemi, F., Baholli, F., \& Guberaj, E. (2015). E-Tailing In Kosovo: The Effect Of Trust, Satisfaction And Service Quality In Achieving Consumer E-Loyalty. Academic Journal of Interdisciplinary Studies, 1(1), 1-11. Https://Doi.Org/10.5901/Ajis.2015.V4n3s1p502

Bani Ismoyo, N. (2018). Service Quality Perception's Effect On Customer Satisfaction And Repurchase Intention. European Business \& Management, 3(3), 37. Https://Doi.Org/10.11648/J.Ebm.20170303.11

Bao, J. (2015). The Impacts Of E-Service Quality On Customers' Repurchase Intention In Platform Online Retailing: An Empirical Investigation. Fourteenth Wuhan International Conference On E-Business, 298-306.

Baskol, M. (2016). The Effects Of E-Retail Service Quality On Repurchase Intention. Business And Economic Research Journal, Volume 7 N.

Buchari, R. A. (2016). Implementasi E-Service Pada Organisasi Publik Di Bidang Pelayanan Publik Di Kelurahan Cibangkong Kecamatan Batununggal Kota Bandung. Sosiohumaniora, 18(3), 235-239. Https:/ / Doi.Org/10.24198/Sosiohumaniora.V18i3.8762

Chen, L., Li, Y. Q., \& Liu, C. H. (2019). How Airline Service Quality Determines The Quantity Of Repurchase Intention - Mediate And Moderate Effects Of Brand Quality And Perceived Value. Journal Of Air Transport Management, 75(October), 185-197. Https:// Doi.Org/10.1016/J.Jairtraman.2018.11.002

Gera, R. (2013). Evaluating The Relationship Of Online Service Quality Dimensions With Satisfaction, Value And Behavioral Outcome. African Journal Of Business Management, 7(10), 754-761. Https:/ / Doi.Org/10.5897/AJBM11.675

Javed, M. K., \& Wu, M. (2019). Effects Of Online Retailer After Delivery Services On Repurchase Intention: An Empirical Analysis Of Customers' Past Experience And Future Confidence With The Retailer. Journal Of Retailing And Consumer Services, (January), 101942. Https:/ / Doi.Org/10.1016/J.Jretconser.2019.101942

Kim, W. H., Cho, J. L., \& Kim, K. S. (2019). The Relationships Of Wine Promotion, Customer Satisfaction, And Behavioral Intention: The Moderating Roles Of 
Customers' Gender And Age. Journal Of Hospitality And Tourism
Management,
39(October Https:/ / Doi.Org/10.1016/J.Jhtm.2019.03.001

Meidita, Y., Suprapto, \& Rokhmawati, R. I. (2016). Pengaruh Kualitas Layanan Terhadap Kepuasan, Kepercayaan Dan Loyalitas Pelanggan Pada ECommerce (Studi Kasus : Berrybenka). Jurnal Pengembangan Teknologi Informasi Dan Ilmu Komputer, 2(11), 5682-5690.

Mojtaba Kaveh. (2012). Role Of Trust In Explaining Repurchase Intention. African Journal Of Business Management, 6(14), 5014-5025. Https:/ / Doi.Org/10.5897/Ajbm11.2625

Nurlita. (2017). Pengaruh E-Service Quality, Dan Kepercayaan Online Terhadap Minat Pembelian Toko Online Di Tokopedia, 6(2), 83-93.

Picaully, M. R. (2018). Pengaruh Kepercayaan Pelanggan Terhadap Niat Pembelian Gadget Di Shopee Indonesia. Jurnal Manajemen Maranatha, 18(1), 31-40. Https://Doi.Org/10.28932/Jmm.V18i1.1094

Posselt, T., \& Gerstner, E. (2005). Pre-Sale Vs. Post-Sale E-Satisfaction: Impact On Repurchase Intention And Overall Satisfaction. Journal Of Interactive Marketing, 19(4), 35-47. Https:/ / Doi.Org/10.1002/Dir.20048

Razak, N. S., Ahmad, A. H., \& Marimuthu, M. (2016). The Effect Of Website Quality On Repurchase Intention In Travel Agency's Website In Malaysia. Asia Pacific Institute Of Advanced Research (Apiar), Valume 2.

Razak, N. S. A., Marimuthu, M., Omar, A., \& Mamat, M. (2014). Trust And Repurchase Intention On Online Tourism Services Among Malaysian Consumers. Procedia - Social And Behavioral Sciences, 130, 577-582. Https:/ / Doi.Org/10.1016/J.Sbspro.2014.04.067

Robert M. Morgan And Shelby D. Hunt Reviewed. (1994). The CommitmentTrust Theory Of Relationship Marketing. Journal Of Marketing, 58(3), 20-30. Https:/ / Doi.Org/10.1016/0022-0531(82)90041-2

Rostami, A., Amir Khani, A. H., \& Soltani, G. (2016). The Impact Of E-Service Quality On The Improvement Of The Level Of Communication With Customers Of Bank Melli Branches In South Tehran Affairs Office. Procedia Economics And Finance, 36(16), 448-455. Https://Doi.Org/10.1016/S22125671(16)30063-6

Saleem, M. A., Zahra, S., \& Yaseen, A. (2017). Impact Of Service Quality And Trust On Repurchase Intentions - The Case Of Pakistan Airline Industry. Asia Pacific Journal of Marketing And Logistics, 29(5), 1136-1159. Https:/ / Doi.Org/10.1108/APJML-10-2016-0192

Santoso, A., \& Aprianingsih, A. (2017). The Influence Of Perceived Service And E-Service Quality To Repurchase Intention The Mediating Role Of Customer Satisfaction Case Study: Go-Ride In Java. Journal Of Business And Management, 6(1), 12.

Saragih, H., \& Ramdhany, R. (2016). Pengaruh Intensi Pelanggan Dalam Berbelanja Online Kembali Melalui Media Teknologi Informasi Forum Jual Beli (Fjb) Kaskus. Jurnal Sistem Informasi, 8(2), 100. Https://Doi.Org/10.21609/Jsi.V8i2.331

Setyorini, R., \& Prima, R. (2015). The Effect Of Trust Towards Online Repurchase Intention With Perceived Usefulness As An Intervening Variable : A Study 
On KASKUS Marketplace Customers. The Asian Journal Of Technology Management, 9(Iicies), 1-7.

Shahrokh, Z. D., Oveisi, N., \& Timasi, S. M. (2013). The Effects Of Customer Loyalty On Repurchase Intention In B2C E-Commerce- A Customer Loyalty Perspective. Journal Of Basic And Applied Scientific Research, 3(6), 636-644. Retrieved Https://Www.Researchgate.Net/Publication/311027301_The_Effects_Of_C ustomer_Loyalty_On_Repurchase_Intention_In_B2C_E-Commerce-

_A_Customer_Loyalty_Perspective

Zeng, F., Hu, Z., Chen, R., \& Yang, Z. (2009). Determinants Of Online Service Satisfaction And Their Impacts On Behavioural Intentions. Total Quality Management And Business Excellence, 20(9), 953-969. Https:/ / Doi.Org/10.1080/14783360903181719 